Int. J. Electrochem. Sci., 11 (2016) 9228 - 9244

\title{
Structural, Morphological and Electrochemical Impedance Study of CS:LiTf based Solid Polymer Electrolyte: Reformulated Arrhenius Equation for Ion Transport Study
}

\author{
Shujahadeen B. Aziz, ${ }^{1,2, *}$, M. F. Z. Kadir ${ }^{3}$, Z. H Z. Abidin ${ }^{4}$ \\ ${ }^{1}$ Advanced Materials Research Lab., School of Science-Department of Physics, Faculty of Science \\ and Science Education, University of Sulaimani, Sulaimani, Kurdistan Regional Government-Iraq \\ ${ }^{2}$ Development Center for Research and Training (DCRT), University of Human Development, Qrga \\ Street, Sulaimani, Kurdistan Regional Government-Iraq. \\ ${ }^{3}$ Centre for Foundation Studies in Science, University of Malaya, 50603 Kuala Lumpur, Malaysia \\ ${ }^{4}$ Department of Physics, Faculty of Science, University of Malaya, 50603 Kuala Lumpur, Malaysia \\ *E-mail: shujaadeen78@yahoo.com
}

doi: $10.20964 / 2016.11 .18$

Received: 31 July 2016 / Accepted: 3 September 2016 / Published: 10 October 2016

This paper discusses ion conduction mechanism in terms of reformulated Arrhenius equation. Understanding the fundamental concepts of $\mathrm{Li}$ ion transport is crucial for $\mathrm{Li}$ battery technology. Structural and morphological investigations are significant to understand the structure-properties relationships. The broadening of X-ray peaks of chitosan upon the addition of LiTf salt reveals that the crystalline domains are reduced. The SEM micrographs reveal that the samples have a smooth surface. Electrochemical impedance spectroscopy (EIS) was used to obtain the electrical and dielectric parameters. The dielectric constant and DC ionic conductivity follows the same trend with salt concentration. The behavior of Arrhenius and modified Arrhenius equations versus temperature are clarified. The influence of dielectric constant on DC conductivity experimentally achieved. The reformulated Arrhenius equation $\left(\sigma_{\left(\varepsilon^{\prime}, T\right)}=\sigma_{o} \exp ^{\left(-\frac{E_{a}}{K_{B} \varepsilon^{\prime} T}\right)}\right.$ ) exhibited more linearity between the DC conductivity and $1000 /\left(\varepsilon^{\prime} \times \mathrm{T}\right)$. The shortcoming of Arrhenius equation can be understood from the less linear behavior of DC conductivity versus 1000/T. The pre-exponential factor is almost constant at different temperature and independent on dielectric constant. The calculated activation energy from the reformulated Arrhenius equation is greater than that obtained from Arrhenius equation.

Keywords: Polymer electrolyte; XRD and SEM analysis; Dielectric constant and DC conductivity; reformulated Arrhenius equation. 
(C) 2016 The Authors. Published by ESG (www.electrochemsci.org). This article is an open access article distributed under the terms and conditions of the Creative Commons Attribution license (http://creativecommons.org/licenses/by/4.0/). 